\title{
Complete genome sequence of Methanothermus fervidus type strain $\left(\mathrm{V}^{24 \mathrm{~S}^{\mathrm{T}}}\right)$
}

Iain Anderson ${ }^{1}$, Olivier Duplex Ngatchou Djao ${ }^{2}$, Monica Misra ${ }^{1,3}$, Olga Chertkov ${ }^{1,3}$, Matt Nolan ${ }^{1}$, Susan Lucas ${ }^{1}$, Alla Lapidus ${ }^{1}$, Tijana Glavina Del Rio ${ }^{1}$, Hope Tice ${ }^{1}$, Jan-Fang Cheng ${ }^{1}$, Roxanne Tapia ${ }^{1,3}$, Cliff Han ${ }^{1,3}$, Lynne Goodwin ${ }^{1,3}$, Sam Pitluck', Konstantinos Liolios ${ }^{1}$, Natalia Ivanova ${ }^{1}$, Konstantinos Mavromatis ${ }^{1}$, Natalia Mikhailova ${ }^{1}$, Amrita Pati ${ }^{1}$, Evelyne Brambilla ${ }^{4}$, Amy Chen ${ }^{5}$, Krishna Palaniappan ${ }^{5}$, Miriam Land ${ }^{1,6}$, Loren Hauser ${ }^{1,6}$, Yun-Juan Chang ${ }^{1,6}$, Cynthia D. Jeffries ${ }^{1,6}$, Johannes Sikorski ${ }^{4}$, Stefan Spring ${ }^{4}$, Manfred Rohde ${ }^{2}$, Konrad Eichinger ${ }^{7}$, Harald Huber ${ }^{7}$, Reinhard Wirth ${ }^{7}$, Markus Göker ${ }^{4}$, John C. Detter ${ }^{1}$, Tanja Woyke ${ }^{1}$, James Bristow ${ }^{1}$, Jonathan A. Eisen ${ }^{1,8}$, Victor Markowitz ${ }^{5}$, Philip Hugenholtz ${ }^{1}$, Hans-Peter Klenk $^{4}$, and Nikos C. Kyrpides ${ }^{1 *}$

${ }^{1}$ DOE Joint Genome Institute, Walnut Creek, California, USA

${ }^{2}$ HZI - Helmholtz Centre for Infection Research, Braunschweig, Germany

${ }^{3}$ Los Alamos National Laboratory, Bioscience Division, Los Alamos, New Mexico, USA

${ }^{4}$ DSMZ - German Collection of Microorganisms and Cell Cultures GmbH, Braunschweig, Germany

${ }^{5}$ Biological Data Management and Technology Center, Lawrence Berkeley National Laboratory, Berkeley, California, USA

${ }^{6}$ Oak Ridge National Laboratory, Oak Ridge, Tennessee, USA

${ }^{7}$ University of Regensburg, Archaeenzentrum, Regensburg, Germany

${ }^{8}$ University of California Davis Genome Center, Davis, California, USA

*Corresponding author: Nikos C. Kyrpides

Keywords: hyperthermophile, strictly anaerobic, motile, Gram-positive, chemolithoautotroph, Methanothermaceae, Euryarchaeota, GEBA.

Methanothermus fervidus Stetter 1982 is the type strain of the genus Methanothermus. This hyperthermophilic genus is of a thought to be endemic in Icelandic hot springs. $M$. fervidus was not only the first characterized organism with a maximal growth temperature $\left(97^{\circ} \mathrm{C}\right)$ close to the boiling point of water, but also the first archaeon in which a detailed functional analysis of its histone protein was reported and the first one in which the function of 2,3-cyclodiphosphoglycerate in thermoadaptation was characterized. Strain V24S ${ }^{\top}$ is of interest because of its very low substrate ranges, it grows only on $\mathrm{H}_{2}+\mathrm{CO}_{2}$. This is the first completed genome sequence of the family Methanothermaceae. Here we describe the features of this organism, together with the complete genome sequence and annotation. The 1,243,342 bp long genome with its 1,311 protein-coding and 50 RNA genes is a part of the Genomic Encyclopedia of Bacteria and Archaea project.

\section{Introduction}

Strain V24S ${ }^{\mathrm{T}}$ (= DSM $2088=$ ATCC $43054=$ JCM 10308 ) is the type strain of Methanothermus fervidus [1]. Together with $M$. sociabilis, there are currently two species placed in the genus Methanothermus. The strain $\mathrm{V}_{24 \mathrm{~S}^{\mathrm{T}}}$ was isolated from an anaerobic Icelandic spring $[1,2]$ and $M$. sociabilis from a continental solfatara field in Iceland [2]. Since any attempt to isolate Methanothermus from similar places (Italy, the Azores, Yellowstone National Park) was without success, Lauerer et al. (1986) have speculated that strains of Methanothermus may exist endemically within Iceland [2]. The genus name derives from the Latin word " $m e$ - thanum", methane, and from the Greek adjective "therme", meaning heat, which refers to a methane producing organism living in a hot niche [1]. The species epithet fervidus comes from the Latin adjective "fervidus", glowing hot, burning, fervent, because of its growth in almost-boiling water [1]. No further cultivated strains belonging to the species $M$. fervidus have been described so far. Here we present a summary classification and a set of features for M. fervidus strain V24ST, together with the description of the complete genomic sequencing and annotation. 


\section{Classification and features}

The original 16S rRNA gene sequence of strain V24S $^{\mathrm{T}}$ (M59145) shows 92\% sequence identity with the 16S rRNA gene of M. sociabilis (AF095273) [2] (Figure 1) and 88\% identity with an uncultured clone, NRA12 (HM041913). The highest sequence similarities of the strain V24S $16 \mathrm{~S}$ rRNA to metagenomic libraries (env_nt) were $87 \%$ or less (status August 2010), indicating that members of the species, genus and even family are poorly represented in the habitats screened so far. The $16 \mathrm{~S}$ rRNA gene sequence of strain $\mathrm{V} 24 \mathrm{~S}^{\mathrm{T}}$ was compared with the most recent release of the Greengenes database using BLAST [13] and the relative frequencies weighted by BLAST scores, of taxa and keywords within the 250 best hits were determined. The five most frequent genera were Methanobacterium (55.3\%), Methanothermobacter (23.5\%), Methanobrevibacter (12.8\%), Methanothermus (5.7\%) and Thermococcus $(1.7 \%)$. The five most frequent keywords within the labels of environmental samples which yielded hits were 'anaerobic' (7.1\%), 'sludge' (4.7\%), 'microbial' (3.7\%), 'archaeal' (3.5\%) and 'temperature' (3.4\%). Besides 'sludge', these keywords fit well to what is known from the taxonomy, ecology, and physiology of strain V24ST. Environmental samples which yielded hits of a higher score than the highest scoring species were not found. The genome of $M$. fervidus contains two rRNA operons. One of these operons has a closely linked 7S RNA gene, encoding the RNA component of signal recognition particle [14].

Figure 1 shows the phylogenetic neighborhood of $M$. fervidus $\mathrm{V} 24 \mathrm{~S}^{\mathrm{T}}$ in a $16 \mathrm{~S}$ rRNA based tree. The sequences of the two 16S rRNA gene copies in the genome of Methanothermus fervidus DSM 2088 differ from each other by up to four nucleotides, and differ by up to 17 nucleotides from the previously published 16S rRNA sequence (M59145), which contains 87 ambiguous base calls.

Although the cells of the strain V24ST do not contain a typical bacterial peptidoglycan, they stain Gram-positive. Cells are curved rods, 1-3 $\mu \mathrm{m}$ long and $0.3-0.4 \mu \mathrm{m}$ in width (Figure 2 and Table 1), occurring singly and in pairs, with a doubling time of 170 minutes [1]. Round, smooth, opaque, and slightly grayish colonies of 1 to $3 \mathrm{~mm}$ in diameter were observed on modified MM-medium plates containing trace amounts of solid sodium dithionite, sodium silicate solution and resazurin [1]. Strain V24S is strictly anaerobic and strictly autotrophic [26]. Due to the low melting point of agar, strain V24ST could do not be grown on agar. Cells did not grow at temperatures below $61^{\circ} \mathrm{C}$ or above $97^{\circ} \mathrm{C}$; the optimal temperature was $83^{\circ} \mathrm{C}$ [1]. Growth occurs at a slightly acidic $\mathrm{pH}$ and equal to 6.5 , while no growth could be observed at $\mathrm{pH}$ above 7.0 [1]. In comparison, $M$. sociabilis grows at the temperatures ranged between $65^{\circ} \mathrm{C}$ and $97^{\circ} \mathrm{C}$, with the optimal temperature at $88^{\circ} \mathrm{C}$, its $\mathrm{pH}$ for growth being acidic to neutral (pH 5.5 to 7.5) [27]. Strain V24ST produces methane from $\mathrm{H}_{2}+\mathrm{CO}_{2}$, whereas acetate and formate are not used [1,27]. The addition of 2-mercapto-ethanesulfonic acid (coenzyme M) enhances growth, especially when small inoculates are used [1]. In artificial medium, yeast extract is required as an organic factor for growth [1]. Strain $\mathrm{V}_{24 S^{\mathrm{T}}}$ gains energy by oxidizing $\mathrm{H}_{2}$ to reduce $\mathrm{CO}_{2}$ as the terminal electron acceptor $[26,28]$. At the time of isolation, strain $\mathrm{V}^{24 \mathrm{~S}^{\mathrm{T}}}$ was described to be nonmotile [1]. Later, strain $\mathrm{V}^{24 \mathrm{~S}^{\mathrm{T}}}$ as well as $M$. sociabilis were described to be motile via bipolar peritrichous 'flagella', which was taken to indicate motility [28]. These cell surface appendages, however, were recently determined to have a diameter of 5-6 $\mathrm{nm}$, and therefore, very probably, represent not organelles used for motility, but for adhesion [R Wirth et al., unpublished]. The genome does not contain any flagellar genes. M. fervidus produces large intracellular potassium concentrations and amounts of 2,3-cyclic diphosphoglycerate, which are both thought to be involved in the thermoadaptation of $M$. fervidus $[29,30]$. Moreover, the DNAbinding protein HMf (histone M. fervidus), which binds to double stranded DNA molecules and increases their resistance to thermal denaturation, has been of interest in M. fervidus [31]. A partial amino acid sequence analysis of the Dglyceraldehyde-3-phosphate dehydrogenase of $M$. fervidus shows high sequence similarity to the enzymes from eubacteria and from the cytoplasm of eukaryotes [32]. This enzyme reacts with both $\mathrm{NAD}^{+}$and $\mathrm{NADP}^{+}[32,33]$ and is not inhibited by pentalenolactone [32]. However, the enzyme activity is low at temperatures below $40^{\circ} \mathrm{C}$, but it is intrinsically stable only up to $75^{\circ} \mathrm{C}$ [32], which is interesting as growth of $M$. fervidus may occur up to $97^{\circ} \mathrm{C}$ [1]. Also, the biochemistry of triose-phosphate isomerase, which catalyzes the interconversion of dihydroxyacetone phosphate (DHAP) and glyceraldehyde 3-phosphate (GAP) in the reversible Embden-Meyerhof-Parnas (EMP) pathway, has been studied to some detail in M. fervidus [34]. 


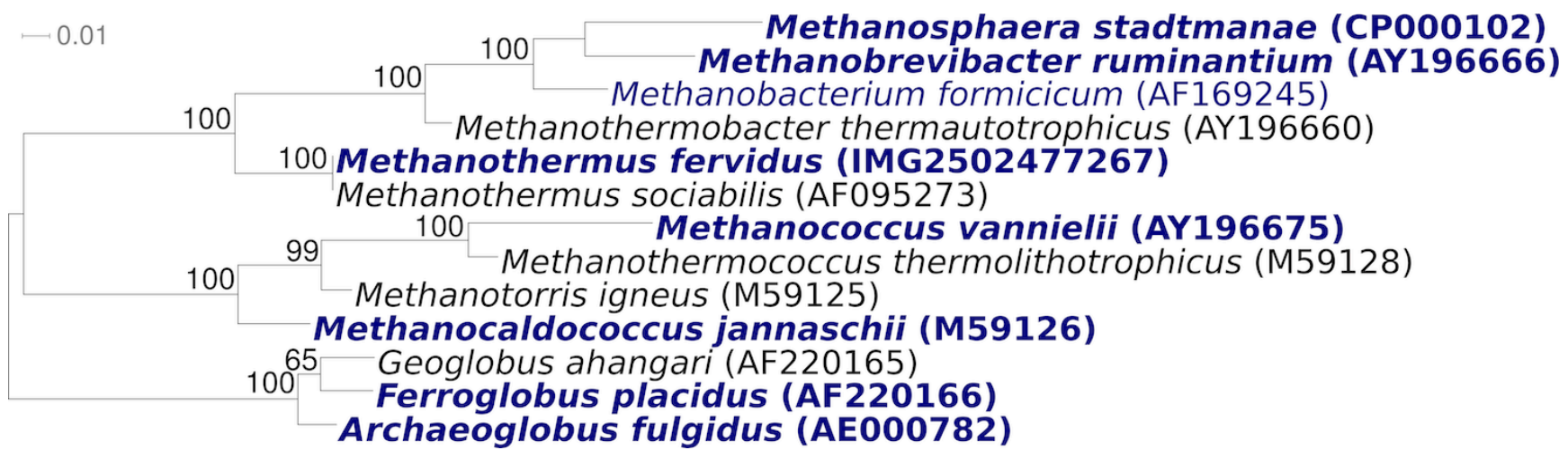

Figure 1. Phylogenetic tree highlighting the position of $M$. fervidus $\mathrm{V} 24 \mathrm{~S}^{\top}$ relative to the other type strains within the family Methanothermaceae. The tree was inferred from 1,249 aligned characters $[3,4]$ of the $16 \mathrm{~S}$ rRNA gene sequence under the maximum likelihood criterion [5] and rooted in accordance with the current taxonomy [6]. The branches are scaled in terms of the expected number of substitutions per site. Numbers above branches are *support values from 100 bootstrap replicates [7] if larger than 60\%. Lineages with type strain genome sequencing projects registered in GOLD [8] are shown in blue, published genomes in bold [9-12].

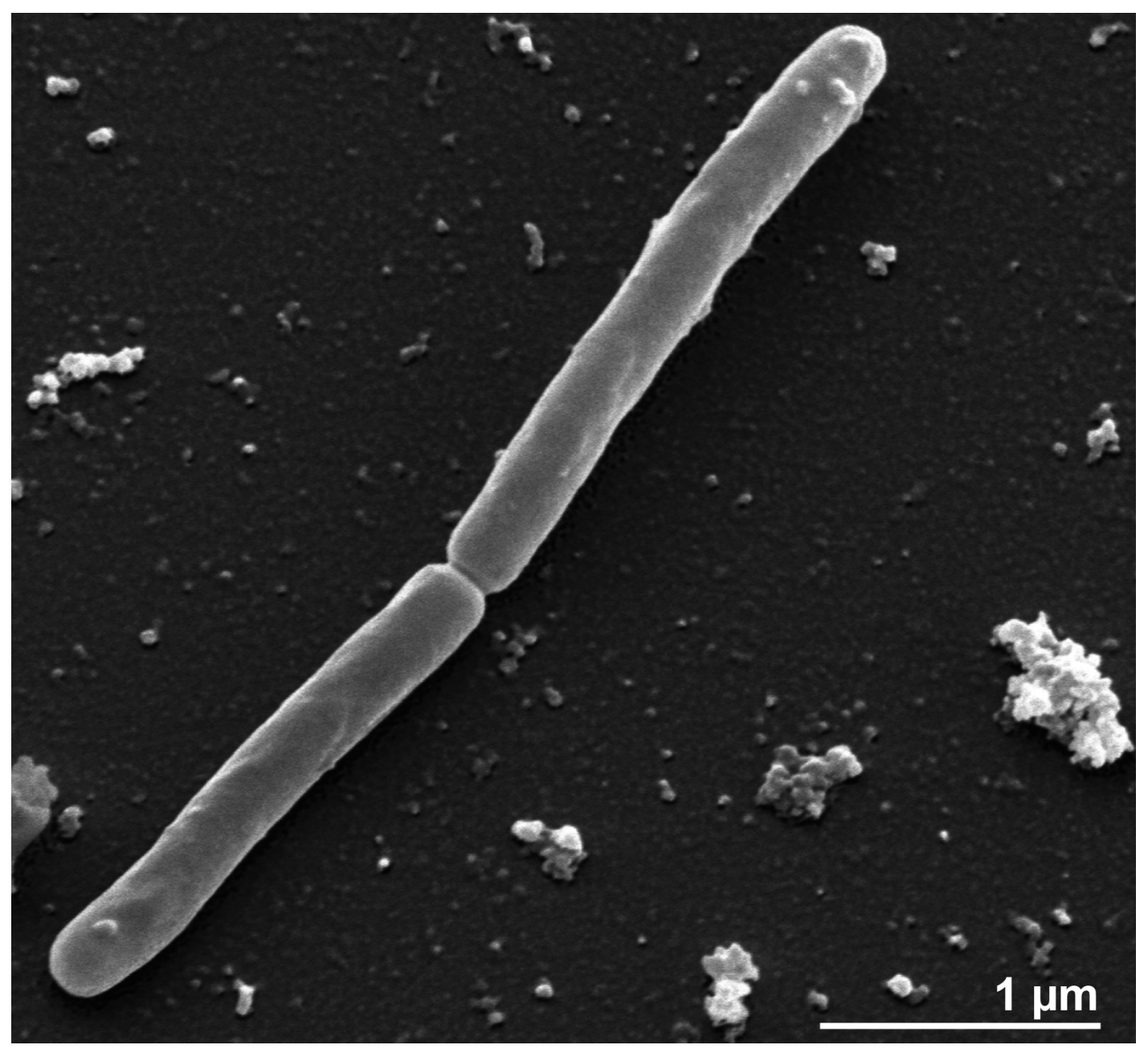

Figure 2. Scanning electron micrograph of $M$. fervidus $\mathrm{V} 24 \mathrm{~S}^{\top}$ 


\section{Chemotaxonomy}

The cell envelope of the strain V24S $\mathrm{S}^{\mathrm{T}}$ consists of a double-layer of pseudomurein and protein, while the cell wall contains pseudomurein consisting of $\mathrm{N}$-acetyl-glucosamine, $\mathrm{N}$-acetyl-galactosamine, $\mathrm{N}$ talosaminuronic acid, glutamic acid, alanine, and lysine $[1,2]$.

$M$. fervidus contains approximately $50 \%$ diethers, $25 \%$ diglycerol tetraethers and $25 \%$ of an unknown component moving slower than the tetraethers when examined by thin layer chromatography [2]. Here, $M$. fervidus differs from $M$. sociabilis, which lacks the unknown component while its diether and tetraethers were found at about equal proportions [2]. The diethers of M. fervidus contain only $\mathrm{C}_{20}$ phytanyl chains while the tetraethers include about $98-99 \% \mathrm{C}_{40}$ biphytane and only some trace of $\mathrm{C}_{40}$ monocyclic biphytane [2]. Besides an unknown core lipid (FU, 31\% of total core lipids, migrates slower than caldarchaeol by thin layer chromatography), other core lipids found in $M$. fervidus were caldarchaeol (60\%), archaeol (4\%) and others (5\%) [35,36]. Interestingly, M. fervidus also differs from $M$. sociabilis regarding the glycolipid composition with four glycolipids and about equal proportions of five phospholipids and only three phospholipids for $M$. sociabilis [2].

Table 1. Classification and general features of $M$. fervidus $V 24 S^{\top}$ according to the MIGS recommendations [15]

\begin{tabular}{|c|c|c|c|}
\hline MIGS ID & Property & Term & Evidence code \\
\hline & \multirow{8}{*}{ Current classification } & Domain Archaea & TAS [16] \\
\hline & & Phylum Euryarchaeota & TAS $[17,18]$ \\
\hline & & Class Methanobacteria & TAS $[18,19]$ \\
\hline & & Order Methanobacteriales & TAS [20-22] \\
\hline & & Family Methanothermaceae & TAS $[1,23]$ \\
\hline & & Genus Methanothermus & TAS $[1,23]$ \\
\hline & & Species Methanothermus fervidus & TAS $[1,23]$ \\
\hline & & Type strain V24S & TAS [1] \\
\hline & Gram stain & positive & TAS [1] \\
\hline & Cell shape & straight to curved, single and in pair rods & TAS [1] \\
\hline & Motility & non-motile & TAS [1] \\
\hline & Sporulation & not reported & NAS \\
\hline & Temperature range & $61^{\circ} \mathrm{C}-97^{\circ} \mathrm{C}$ & TAS [1] \\
\hline & Optimum temperature & $83^{\circ} \mathrm{C}$ & TAS [1] \\
\hline & Salinity & not reported & NAS \\
\hline \multirow[t]{3}{*}{ MIGS-22 } & Oxygen requirement & strict anaerobic & TAS [1] \\
\hline & Carbon source & $\mathrm{CO}_{2}$ & TAS [1] \\
\hline & Energy source & $\mathrm{H}_{2}+\mathrm{CO}_{2}$ & TAS [1] \\
\hline MIGS-6 & Habitat & solfataric fields & TAS [1] \\
\hline MIGS-15 & Biotic relationship & not reported & NAS \\
\hline \multirow[t]{3}{*}{ MIGS-14 } & Pathogenicity & no & NAS \\
\hline & Biosafety level & 1 & TAS [24] \\
\hline & Isolation & Icelandic hot spring & TAS [1] \\
\hline MIGS-4 & Geographic location & Kerlingarfjöll mountains, Iceland & TAS [1] \\
\hline MIGS-5 & Sample collection time & 1979 & NAS \\
\hline MIGS-4.1 & Latitude & 64.65 & \\
\hline MIGS-4.2 & Longitude & 19.25 & NAS \\
\hline MIGS-4.3 & Depth & surface & TAS [1] \\
\hline MIGS-4.4 & Altitude & $1.477 \mathrm{~m}$ & NAS \\
\hline
\end{tabular}

Evidence codes - IDA: Inferred from Direct Assay (first time in publication); TAS: Traceable Author Statement (i.e., a direct report exists in the literature); NAS: Non-traceable Author Statement (i.e., not directly observed for the living, isolated sample, but based on a generally accepted property for the species, or anecdotal evidence). These evidence codes are from of the Gene Ontology project [25]. If the evidence code is IDA, then the property was directly observed by one of the authors or an expert mentioned in the acknowledgements 


\section{Genome sequencing and annotation} Genome project history

This organism was selected for sequencing on the basis of its phylogenetic position [37], and is part of the Genomic Encyclopedia of Bacteria and Archaea project [38]. The genome project is deposited in the Genome OnLine Database [8] and the com- plete genome sequence is deposited in GenBank. Sequencing, finishing and annotation were performed by the DOE Joint Genome Institute (JGI). A summary of the project information is shown in Table 2 .

Table 2. Genome sequencing project information

\begin{tabular}{lll}
\hline MIGS ID & Property & Term \\
\hline MIGS-31 & Finishing quality & Finished \\
MIGS-28 & Libraries used & Three genomic libraries: one 454 pyrosequence standard library, one \\
MIGS-29 & Sequencing platforms & 454 PE library (17.8 kb insert size), one Illumina library \\
MIGS-31.2 & Sequencing coverage & $530 \times$ Illumina; 75.0 $\times$ pyrosequence \\
MIGS-30 & Assemblers & Newbler version 2.0.00.20-PostRelease-11-05-2008-gcc-3.4.6, phrap \\
MIGS-32 & Gene calling method & Prodigal 1.4, GenePRIMP \\
& INSDC ID & CP002278 \\
& Genbank Date of Release & November 5, 2010 \\
& GOLD ID & Gc01509 \\
& NCBI project ID & 33689 \\
& Database: IMG-GEBA & 2502422313 \\
MIGS-13 & Source material identifier & DSM 2088 \\
& Project relevance & Tree of Life, GEBA \\
\hline
\end{tabular}

\section{Growth conditions and DNA isolation}

M. fervidus V24ST, DSM 2088, was grown anaerobically in culture vessels made of type III glass (alkali-rich soda lime glass) in DSMZ medium 203 (M. fervidus medium) [39] at $83^{\circ} \mathrm{C}$. DNA was isolated from 0.5-1 g of cell paste using Qiagen Genomic 500 DNA Kit (Qiagen, Hilden, Germany) following the standard protocol as recommended by the manufacturer, with a modified cell lysis step. The modified lysis mixture contained only $100 \mu$ lysozyme, but additional $58 \mu \mathrm{l}$ achromopeptidase, lysostaphine, mutanolysin, each, for over night incubation at $35^{\circ} \mathrm{C}$ on a shaker. Proteinase $\mathrm{K}$ digestion was reduced to $200 \mu \mathrm{l}$ for $1 \mathrm{~h} 37^{\circ} \mathrm{C}$.

\section{Genome sequencing and assembly}

The genome was sequenced using a combination of Illumina and 454 sequencing platforms. All general aspects of library construction and sequencing can be found at the JGI website [40]. Pyrosequencing reads were assembled using the Newbler assembler version 2.0.00.20-PostRelease-1105-2008-gcc-3.4.6 (Roche). The initial Newbler assembly consisting of 24 contigs in one scaffold was converted into a phrap assembly [41] by making fake reads from the consensus, collecting the read pairs in the 454 paired end library. Illumina GAii sequencing data (636 Mb) was assembled with Velvet [42] and the consensus sequences were shredded into $1.5 \mathrm{~kb}$ overlapped fake reads and assembled together with the 454 data. 454 Draft assembly was based on $96.5 .0 \mathrm{Mb} 454 \mathrm{draft}$ data and all of the 454 paired end data. Newbler parameters are -consed -a 50 -l 350 -g -m -ml 20. The Phred/Phrap/Consed software package [41] was used for sequence assembly and quality assessment in the subsequent finishing process. After the shotgun stage, reads were assembled with parallel phrap (High Performance Software, LLC). Possible mis-assemblies were corrected with gapResolution [40], Dupfinisher, or sequencing cloned bridging PCR fragments with subcloning or transposon bombing (Epicentre Biotechnologies, Madison, WI) [43]. Gaps between contigs were closed by editing in CONSED and additional sequencing reactions were necessary to close gaps 
and/or to raise the quality of the finished sequence. Illumina reads were also used to correct potential base errors and increase consensus quality using a software Polisher developed at JGI [44]. The error rate of the completed genome sequence is less than 1 in 100,000. Together, the combination of the Illumina and 454 sequencing platforms provided $605 \times$ coverage of the genome. The final assembly contained 267,328 pyrosequence and 17,666,667 Illumina reads.

\section{Genome annotation}

Genes were identified using Prodigal [45] as part of the Oak Ridge National Laboratory genome annotation pipeline, followed by a round of manual curation using the JGI GenePRIMP pipeline [46]. The predicted CDSs were translated and used to search the National Center for Biotechnology Information (NCBI) nonredundant database, Uni-
Prot, TIGRFam, Pfam, PRIAM, KEGG, COG, and InterPro databases. Additional gene prediction analysis and functional annotation was performed within the Integrated Microbial Genomes - Expert Review (IMG-ER) platform [47].

\section{Genome properties}

The genome consists of a 1,243,342 bp long chromosome with a $31.6 \%$ GC content (Table 3 and Figure 3). Of the 1,361 genes predicted, 1,311 were protein-coding genes, and 50 RNAs; twenty eight pseudogenes were also identified. The majority of the protein-coding genes $(74.8 \%)$ were assigned with a putative function while the remaining ones were annotated as hypothetical proteins. The distribution of genes into COGs functional categories is presented in Table 4.

Table 3. Genome Statistics

\begin{tabular}{lrr}
\hline Attribute & Value & \% of Total \\
\hline Genome size (bp) & $1,243,342$ & $100.00 \%$ \\
DNA coding region (bp) & $1,163,294$ & $93.56 \%$ \\
DNA G+C content (bp) & 393,356 & $31.64 \%$ \\
Number of replicons & 1 & $100.00 \%$ \\
Extrachromosomal elements & 0 & \\
Total genes & 1,361 & $100.00 \%$ \\
RNA genes & 50 & $3.67 \%$ \\
rRNA operons & 2 & $0.15 \%$ \\
Protein-coding genes & 1,311 & $96.33 \%$ \\
Pseudo genes & 28 & $2.06 \%$ \\
Genes with function prediction & 1,018 & $74.80 \%$ \\
Genes in paralog clusters & 100 & $7.35 \%$ \\
Genes assigned to COGs & 1,126 & $82.73 \%$ \\
Genes assigned Pfam domains & 1,144 & $84.06 \%$ \\
Genes with signal peptides & 109 & $8.01 \%$ \\
Genes with transmembrane helices & 248 & $18.22 \%$ \\
CRISPR repeats & 0 & \\
\hline
\end{tabular}




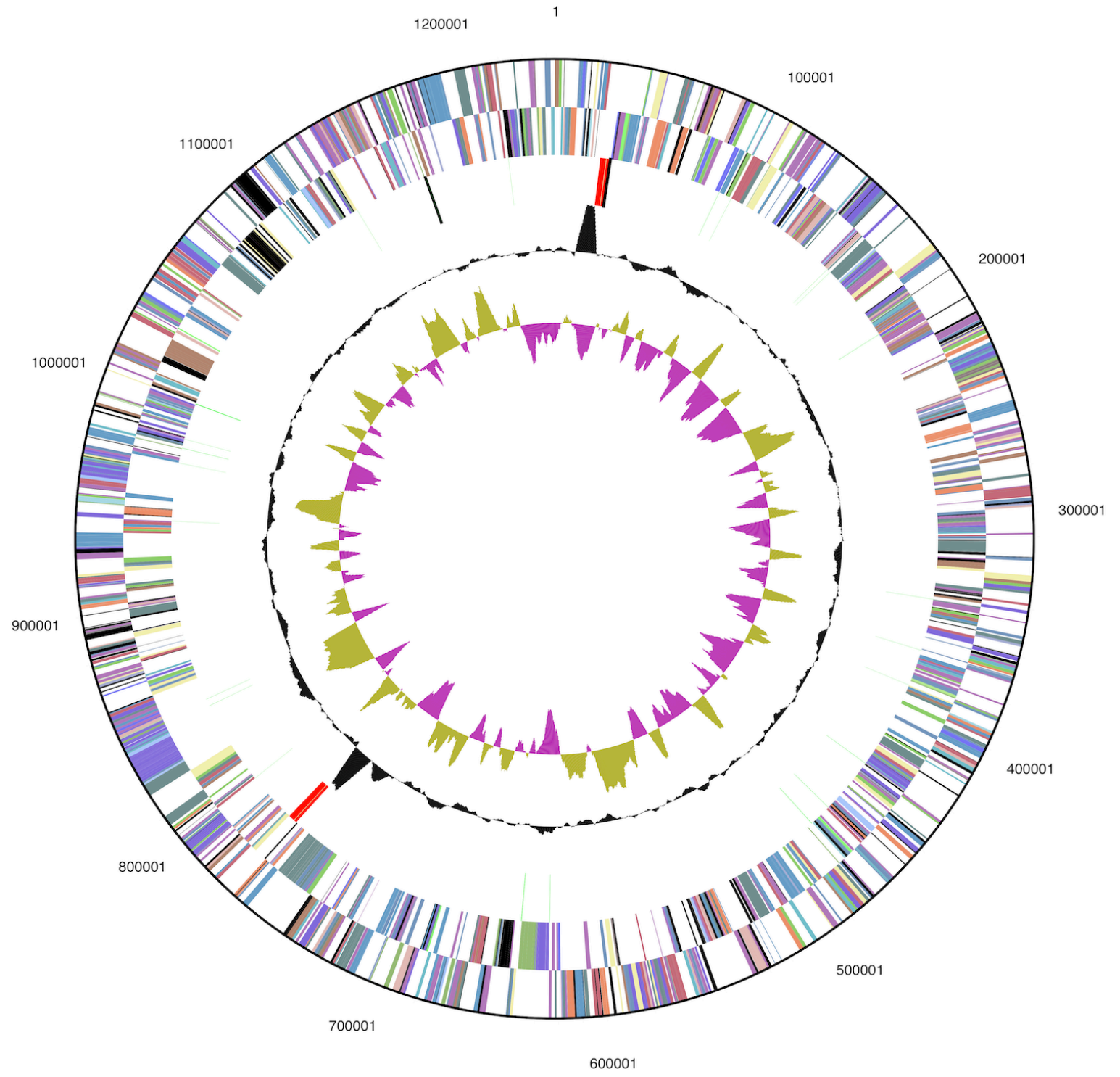

Figure 3. Graphical circular map of the genome. From outside to the center: Genes on forward strand (color by COG categories), Genes on reverse strand (color by COG categories), RNA genes (tRNAs green, rRNAs red, other RNAs black), GC content, GC skew.

Table 4. Number of genes associated with the general COG functional categories

\begin{tabular}{lrrl}
\hline Code & value & \% age & Description \\
\hline J & 144 & 12.2 & Translation, ribosomal structure and biogenesis \\
$\mathrm{A}$ & 2 & 0.2 & RNA processing and modification \\
$\mathrm{K}$ & 47 & 4.0 & Transcription \\
$\mathrm{L}$ & 49 & 4.2 & Replication, recombination and repair \\
$\mathrm{B}$ & 4 & 0.3 & Chromatin structure and dynamics \\
$\mathrm{D}$ & 12 & 1.0 & Cell cycle control, cell division, chromosome partitioning \\
$\mathrm{Y}$ & 0 & 0.0 & Nuclear structure \\
$\mathrm{V}$ & 6 & 0.5 & Defense mechanisms \\
$\mathrm{T}$ & 11 & 0.9 & Signal transduction mechanisms \\
$\mathrm{M}$ & 52 & 4.4 & Cell wall/membrane/envelope biogenesis \\
$\mathrm{N}$ & 1 & 0.1 & Cell motility \\
\hline
\end{tabular}


Table 4 (cont.). Number of genes associated with the general COG functional categories

\begin{tabular}{lrrl}
\hline Code & value & \% age & Description \\
\hline Z & 0 & 0.0 & Cytoskeleton \\
W & 0 & 0.0 & Extracellular structures \\
U & 14 & 1.2 & Intracellular trafficking and secretion, and vesicular transport \\
O & 46 & 3.9 & Posttranslational modification, protein turnover, chaperones \\
C & 111 & 9.4 & Energy production and conversion \\
G & 39 & 3.3 & Carbohydrate transport and metabolism \\
E & 88 & 7.5 & Amino acid transport and metabolism \\
F & 47 & 4.0 & Nucleotide transport and metabolism \\
H & 115 & 9.8 & Coenzyme transport and metabolism \\
I & 17 & 1.4 & Lipid transport and metabolism \\
P & 50 & 4.2 & Inorganic ion transport and metabolism \\
Q & 5 & 0.4 & Secondary metabolites biosynthesis, transport and catabolism \\
R & 172 & 14.6 & General function prediction only \\
S & 147 & 12.5 & Function unknown \\
- & 235 & 17.3 & Not in COGs \\
\hline
\end{tabular}

\section{Acknowledgements}

This work was performed under the auspices of the US Department of Energy Office of Science, Biological and Environmental Research Program, and by the University of California, Lawrence Berkeley National Laboratory under contract No. DE-AC02-05CH11231, Lawrence Livermore National Laboratory under Contract No. DE-
AC52-07NA27344, and Los Alamos National Laboratory under contract No. DE-AC02-06NA25396, UTBattelle and Oak Ridge National Laboratory under contract DE-AC05-000R22725, as well as German Research Foundation (DFG) INST 599/1-1.

\section{References}

1. Stetter KO, Thomm M, Winter J, Wildgruber G, Huber H, Zillig W, Jané-Covic D, König H, Palm P, Wunderl S. Methanothermus fervidus, sp. nov., a novel extremely thermophilic methanogen isolated from an icelandic hot spring. Zentralbl Bakteriol Parasitenkd Infektionskr Hyg Abt 1 Orig C2 1981; 2:166-178.

2. Lauerer G, Kristjansson JK, Langworthy TA, König $\mathrm{H}$, Stetter KO. Methanothermus sociabilis sp. nov., a second species within the Methanothermaceae growing at $97^{\circ} \mathrm{C}$. Syst Appl Microbiol 1986; 8:100-105.

3. Castresana J. Selection of conserved blocks from multiple alignments for their use in phylogenetic analysis. Mol Biol Evol 2000; 17:540-552. PubMed

4. Lee C, Grasso C, Sharlow MF. Multiple sequence alignment using partial order graphs. Bioinformatics 2002; 18:452-464. PubMed doi:10.1093/bioinformatics/18.3.452

5. Stamatakis A, Hoover P, Rougemont J. A rapid bootstrap algorithm for the RAxML web servers.

Syst Biol 2008; 57:758-771. PubMed doi:10.1080/10635150802429642

6. Yarza P, Richter M, Peplies J, Euzeby J, Amann R, Schleifer KH, Ludwig W, Glöckner FO, RossellóMóra R. The All-Species Living Tree project: a $16 S$ rRNA-based phylogenetic tree of all sequenced type strains. Syst Appl Microbiol 2008; 31:241-250. PubMed doi:10.1016/j.syapm.2008.07.001

7. Pattengale ND, Alipour M, Bininda-Emonds ORP, Moret BME, Stamatakis A. How many bootstrap replicates are necessary? Lect Notes Comput Sci 2009; 5541:184-200. doi:10.1007/978-3-64202008-7_13

8. Liolios K, Mavromatis K, Tavernarakis N, Kyrpides NC. The Genomes On Line Database (GOLD) in 2007: status of genomic and metagenomic projects and their associated metadata. Nucleic Acids Res 2008; 36:D475-D479. PubMed doi:10.1093/nar/gkm884

9. Bult CJ, White O, Olsen G, Zhou L, Fleischmann R, Sutton G, Blake J, FitzGerald F, Clayton R, Go- 
Anderson et al.

cayne J, et al. Complete genome sequence of the methanogenic archaeon, Methanococcus jannaschii. Science 1996; 273:1058-1073. PubMed doi:10.1126/science.273.5278.1058

10. Fricke WF, Seedorf H, Henne A, Krüer M, Liesegang $\mathrm{H}$, Hedderich R, Gottschalk G, Thauer RK. The genome sequence of Methanosphaera stadtmanae reveals why this human intestinal archaeon is restricted to methanol and $\mathrm{H}_{2}$ for methane formation and ATP synthesis. J Bacteriol 2006; 188:642-658. PubMed doi:10.1128/JB.188.2.642-658.2006

11. Klenk HP, Clayton RA, Tomb JF, White O, Nelson KE, Ketchum KA, Dodson RJ, Gwinn M, Hickey EK, Peterson JD, et al. The complete genome sequence of the hyperthermophilic, sulphatereducing archaeon Archaeoglobus fulgidus. Nature 1997; 390:364-370. PubMed doi:10.1038/37052

12. Leahy SC, Kelly WJ, Altermann E, Ronimus RS, Yeoman CJ, Pacheco DM, Li D, Kong Z, McTavish S, Sang C, et al. The genome sequence of the rumen methanogen Methanobrevibacter ruminantium reveals new possibilities for controlling ruminant methane emissions. PLOS ONE 2010; 5:e8926. PubMed doi:10.1371/journal.pone.0008926

13. DeSantis TZ, Hugenholtz $P$, Larsen N, Rojas $M$, Brodie E, Keller K, Huber T, Dalevi D, Hu P, Andersen G. Greengenes, a chimera-checked $16 \mathrm{~S}$ rRNA gene database and workbench compatible with ARB. App/ Environ Microbiol 2006; 72:50695072. PubMed doi:10.1128/AEM.03006-05

14. Haas ES, Brown JW, Daniels CJ, Reeve JN. Genes encoding the 7S RNA and TRNA ${ }^{\text {Ser }}$ are linked to one of the two rRNA operons in the genome of the extremely thermophilic archaebacterium Methanothermus fervidus. Gene 1990; 90:51-59. PubMed doi:10.1016/0378-1119(90)90438-W

15. Field D, Garrity G, Gray T, Morrison N, Selengut J, Sterk P, Tatusova T, Thomson N, Allen MJ, Angiuoli SV, et al. The minimum information about a genome sequence (MIGS) specification. Nat Biotechnol 2008; 26:541-547. PubMed doi:10.1038/nbt1360

16. Woese CR, Kandler O, Wheelis ML. Towards a natural system of organisms: proposal for the domains Archaea, Bacteria, and Eucarya. Proc Natl Acad Sci USA 1990; 87:4576-4579. PubMed doi:10.1073/pnas.87.12.4576

17. Garrity GM, Holt JG. The Road Map to the Manual. In: Garrity GM, Boone DR, Castenholz RW (eds), Bergey's Manual of Systematic Bacteriology, Second Edition, Volume 1. Springer, New York 2001:119-169.

18. Validation list 85: Validation of publication of new names and new combinations previously effectively published outside the IJSEM. Int I Syst Evol Microbiol 2002; 52:685-690. PubMed doi:10.1099/ijs.0.02358-0

19. Boone DR. Class I. Methanobacteria class. nov. In: Bergey's Manual of Systematic Bacteriology, 2nd ed., vol. 1 (The Archaea and the deeply branching and phototrophic Bacteria) (D.R. Boone and R.W. Castenholz, eds.), SpringerVerlag, New York 2001:p. 213.

20. List 6. Validation of the publication of new names and new combinations previously effectively published outside the IJSB. Int I Syst Bacteriol 1981; 31:215-218. doi:10.1099/00207713-31-2-215

21. Balch WE, Fox GE, Magrum LJ, Woese CR, Wolfe RS. Methanogens: Reevaluation of a unique biological group. Microbiol Rev 1979; 43:260-296. PubMed

22. Judicial Commission of the International Committee on Systematics of Prokaryotes. The nomenclatural types of the orders Acholeplasmatales, Halanaerobiales, Halobacteriales, Methanobacteriales, Methanococcales, Methanomicrobiales, Planctomycetales, Prochlorales, Sulfolobales, Thermococcales, Thermoproteales and Verrucomicrobiales are the genera Acholeplasma, Halanaerobium, Halobacterium, Methanobacterium, Methanococcus, Methanomicrobium, Planctomyces, Prochloron, Sulfolobus, Thermococcus, Thermoproteus and Verrucomicrobium, respectively. Opinion 79. Int I Syst Evol Microbiol 2005; 55:517-518. PubMed doi:10.1099/ijs.0.63548-0

23. List No. 8. Validation of the publication of new names and new combinations previously effectively published outside the IJSB. Int I Syst Bacteriol 1982; 32:266-268. doi:10.1099/00207713$\underline{32-2-266}$

24. Classification of bacteria and archaea in risk groups. http://www.baua.de TRBA 466.

25. Ashburner M, Ball CA, Blake JA, Botstein D, Butler H, Cherry JM, Davis AP, Dolinski K, Dwight SS, Eppig JT, et al. Gene Ontology: tool for the unification of biology. Nat Genet 2000; 25:25-29. $\underline{\text { PubMed doi:10.1038/75556 }}$

26. Stetter KO, Fiala G, Huber G, Huber R, Segerer A. Hyperthermophilic microorganisms. FEMS Microbiol Rev 1990; 75:117-124. doi:10.1111/j.15746968.1990.tb04089.x 
27. Stetter KO. Hyperthermophilic procaryotes. FEMS Microbiol Rev 1996; 18:149-158. doi:10.1111/j.1574-6976.1996.tb00233.x

28. Bonin AS, Boone DR. 2006. The order Methanobacteriales In: M Dworkin, S Falkow, E Rosenberg, KH Schleifer E Stackebrandt (eds), The Prokaryotes, 3. ed, vol. 7. Springer, New York, p. 231-243.

29. Hensel $\mathrm{R}$, König $\mathrm{H}$. Thermoadaptation of methanogenic bacteria by intracellular ion concentration. FEMS Microbiol Lett 1988; 49:75-79. doi:10.1111/j.1574-6968.1988.tb02685.x

30. Lehmacher $A$, Vogt $A B$, Hensel R. Biosynthesis of cyclic 2,3-diphosphoglycerate: Isolation and characterization of 2-phosphoglycerate kinase and cyclic 2,3-diphosphoglycerate synthetase from Methanothermus fervidus. FEBS Lett 1990; 272:94-98. PubMed doi:10.1016/0014$\underline{\text { 5793(90)80456-S }}$

31. Sandman K, Krzycki JA, Dobrinski B, Lurz R, Reeve JN. HMf, a DNA-binding protein isolated from the hyperthermophilic archaeon Methanothermus fervidus, is most closely related to histones. Proc Natl Acad Sci USA 1990; 87:57885791. PubMed doi:10.1073/pnas.87.15.5788

32. Fabry S, Hensel R. Purification and characterization of D-glyceraldehyde-3-phosphate dehydrogenase from the thermophilic archaebacterium Methanothermus fervidus. Eur / Biochem 1987; 165:147-155. PubMed doi:10.1111/j.14321033.1987.tb11205.x

33. Charron $C$, Talfournier $F$, Isupov MN, Littlechild JA, Branlant G, Vitoux B, Aubry A. The crystal structure of D-glyceraldehyde-3-phosphate dehydrogenase from the hyperthermophilic archaeon Methanothermus fervidus in the presence of $\mathrm{NADP}^{+}$at 2.1 A resolution. J Mol Biol 2000; 297:481-500. PubMed doi:10.1006/jmbi.2000.3565

34. Schramm A, Kohlhoff M, Hensel R. Triosephosphate isomerase from Pyrococcus woesei and Methanothermus fervidus. Methods Enzymol 2001; 331:62-77. PubMed doi:10.1016/S0076$\underline{6879(01) 31047-9}$

35. Koga $Y$, Nishihara M, Morii H, AkagawaMatsushita M. Ether polar lipids of methanogenic bacteria: structures, comparative aspects, and biosyntheses. Microbiol Rev 1993; 57:164-182. PubMed

36. Morii $H$, Eguchi $T$, Nishihara M, Kakinuma $K$, König $\mathrm{H}$, Koga $\mathrm{Y}$. A novel ether core lipid with $\mathrm{H}$ - shaped C-isoprenoid hydrocarbon $\mathrm{C}_{80}$ chain from the hyperthermophilic methanogen Methanothermus fervidus. Biochim Biophys Acta 1998; 1390:339-345. PubMed

37. Klenk HP, Göker M. En route to a genome-based classification of Archaea and Bacteria? Syst Appl Microbiol 2010; 33:175-182. PubMed doi:10.1016/j.syapm.2010.03.003

38. Wu D, Hugenholtz P, Mavromatis K, Pukall R, Dalin E, Ivanova NN, Kunin V, Goodwin L, Wu $\mathrm{M}$, Tindall BJ, et al. A phylogeny-driven genomic encyclopaedia of Bacteria and Archaea. Nature 2009; 462:1056-1060. PubMed doi:10.1038/nature08656

39. List of growth media used at DSMZ: http://www.dsmz.de/microorganisms/media_list.p hp.

40. DOE Joint Genome Institute. http://www.jgi.doe.gov

41. The Phred/Phrap/Consed software package http://www.phrap.com.

42. Zerbino DR, Birney E. Velvet: algorithms for de novo short read assembly using de Bruijn graphs. Genome Res 2008; 18:821-829. PubMed doi:10.1101/gr.074492.107

43. Sims D, Brettin T, Detter J, Han C, Lapidus A, Copeland A, Glavina Del Rio T, Nolan M, Chen $\mathrm{F}$, Lucas $\mathrm{S}$, et al. Complete genome sequence of Kytococcus sedentarius type strain $\left(541^{\mathrm{T}}\right)$. Stand Genomic Sci 2009; 1:12-20. doi:10.4056/sigs.761

44. Lapidus A, LaButti K, Foster B, Lowry S, Trong S, Goltsman E. POLISHER: An effective tool for using ultra short reads in microbial genome assembly and finishing. AGBT, Marco Island, FL, 2008.

45. Hyatt $\mathrm{D}$, Chen $\mathrm{GL}$, Locascio PF, Land ML, Larimer FW, Hauser LJ. Podigal ProkaryoticDynamic Programming Genefinding Algorithm. BMC Bioinformatics 2010; 11:119. PubMed doi:10.1186/1471-2105-11-119

46. Pati A, Ivanova N, Mikhailova N, Ovchinikova G, Hooper SD, Lykidis A, Kyrpides NC. GenePRIMP: A gene prediction improvement pipeline for microbial genomes. Nat Methods 2010; 7:455-457. PubMed doi:10.1038/nmeth.1457

47. Markowitz VM, Ivanova NN, Chen IMA, Chu K, Kyrpides NC. IMG ER: a system for microbial genome annotation expert review and curation. Bioinformatics 2009; 25:2271-2278. PubMed doi:10.1093/bioinformatics/btp393 